\title{
Memory training for children with Down syndrome
}

\author{
Frances A. Conners, Celia J. Rosenquist and Lori A. Taylor \\ The University of Alabama, USA
}

\begin{abstract}
One well-established fact concerning cognitive and language development in individuals with Down syndrome is that working memory is particularly poor, with auditory working memory worse than visual working memory. Working memory serves the functions of control, regulation, and active maintenance of information and is critical in daily complex cognitive activities. Thus, there is a strong need to find effective and practical interventions targeted at improving working memory in individuals with Down syndrome. The present paper reviews research on rehearsal training and concludes that it can be used successfully to increase working memory in individuals with Down syndrome. However, there are still questions about whether auditory working memory can be improved reliably, whether improvement can be maintained over the long term, and whether improvement exists beyond any effect of increased attention. We describe our in-progress study which addresses these concerns.
\end{abstract}

Keywords - Down syndrome, memory, training, rehearsal

\section{Introduction}

For some time now it has been understood that, in spite of general low intellectual functioning, individuals with intellectual disabilities have relative strengths and weaknesses (Dykens, Hodapp \& Finucane, 2000; Pennington \& Bennetto, 1998; Pulsifer, 1996). This is true for individuals with Down syndrome. Relative strengths in Down syndrome may be in the areas of implicit memory (Carlesimo, Marotta \& Vicari, 1997; Vicari, 2001; Vicari, Bellucci \& Carlesimo, 2000) and visual-motor processing (Silverstein, Legutki, Friedman \& Takayama, 1982; see Wang, 1996). Relative weaknesses are in language processing (Abbeduto, 2001; Chapman, 1995; 2001; Fowler, Gelman \& Gleitman, 1994) and in working memory (Jarrold \& Baddeley, 2001; Marcell \& Weeks, 1988; McDade \& Adler, 1980). The present paper is concerned with the relative weakness in working memory and prospects for ameliorating it. It begins with a brief discussion of the problem of poor working memory in Down syndrome and continues with a discussion of rehearsal training as a potential solution to this problem. Research has shown that rehearsal training can improve working memory in individuals with Down syndrome. However, three important issues are as yet unresolved-(1) Can auditory working memory be improved reliably?, (2) Can improvement be maintained over the long term?, and (3) Can improvements hold up to more stringent control comparisons? The last section of the paper is a description of our own in-progress rehearsal training study, which was designed with these three issues in mind. Preliminary results from the study allow us to address the first and third of these issues.

\section{The Problem: Poor Auditory Working Memory}

Working memory refers to the memory system that deals immediately with newly encoded information from the environment as well as information from long-term memory that is currently active. It includes short-term memory and largely determines one's memory span - the number of items one can recall immediately. It is known to be limited in capacity and is considered a critical component in information processing. A prominent model of working memory is Baddeley's multicomponent model (Baddeley, 1986; Baddeley \& Hitch, 1974; 1994). In Baddeley's model, there are three components- the central executive, the phonological loop, and the visuo-spatial sketchpad. The central executive coordinates activities of the phonological loop and the visuo-spatial sketchpad, monitors automatic routines, and provides general attentional resources where needed. The phonological loop processes verbal sequential information. It includes a capacity- and time-limited acoustic storage and articulatory control processes that refresh stimulus traces being stored. These articulatory control processes carry out the rehearsal function of the phonological loop. The visuo- 
spatial sketchpad processes visual/spatial information in a capacity- and time-limited visual buffer.

Working memory plays a central and extremely important role in almost every conscious cognitive activity. Because it is capacity- and time-limited and is involved in the control of current processing of activated codes, working memory sets limits on higher-level processing, such as those involved in language (Gathercole \& Baddeley, 1990, 1993), reading (Baddeley, 1982; Kintsch \& van Dijk, 1978), and mathematics (Adams \& Hitch, 1997; Logie, Gilhooly \& Wynn, 1994). For example, when listening to a spoken message, a person hears sounds in a particular order and must somehow interpret their meaning. Working memory coordinates the moment-to-moment processing whereby incoming sounds are interpreted into words, word meanings are accessed, grammatical structures are interpreted, and the meaning of the message is understood. If working memory is extremely limited, then the comprehension process might break down, particularly for long messages.

Researchers have shown that memory span is shorter in individuals with Down syndrome than in typically developing individuals of equivalent mental age (Hulme \& Mackenzie, 1992; Kay-Raining Bird \& Chapman, 1994; Mackenzie \& Hulme, 1987) and also shorter than in individuals with unspecified causes of intellectual disability who are of equivalent chronological age and mental age (Marcell, Harvey \& Cothran, 1988; Marcell, Ridgeway, Sewell \& Whelan, 1995; Marcell \& Weeks, 1988; McDade \& Adler, 1980). Mackenzie and Hulme (1987; Hulme \& Mackenzie, 1992) showed that memory span increased at a slower rate than mental age in adolescents with Down syndrome. Considering that mental age increases more slowly for those with Down syndrome than for those who are typically developing (Wishart, 1996), the memory span development findings are very compelling. They indicate that, with age, the memory span impairment in Down syndrome becomes more and more severe.

Memory span is limited in Down syndrome especially when materials are presented auditorily rather than visually (Broadley, MacDonald \& Buckley, 1995; Jarrold, Baddeley \& Hewes, 1999; Marcell et al., 1988; McDade \& Adler, 1980) even when thorough hearing screenings have been made (Kay-Raining Bird \& Chapman, 1994; Marcell \& Armstrong, 1982). The memory span impairment seems unrelated to a general sequential processing impairment (Kay-Raining Bird \& Chapman, 1994; Marcell \& Weeks, 1988), to distractibility (Marcell et al., 1988), to storage capacity limitations (McDade \& Adler, 1980), or to oral responding demands (Marcell \& Weeks, 1988). It has been suggested that the impairment is related to poor long-term retrieval of phonological codes (Varnhagan, Das \& Varnhagen, 1987), to weakness in the rehearsal function of the phonological loop (Hulme \& Mackenzie, 1992, but see Jarrold \& Baddeley, 2001; Jarrold, Baddeley \& Hewes, 2000), and/or to poor central executive control (Vicari, Carlesimo \& Caltagirone, 1995).
Given the critical role of working memory in so many aspects of cognition, it is extremely important to examine ways in which individuals with Down syndrome can improve their working memory function. Auditory working memory, which involves the functioning of the phonological loop, supports the development of language comprehension and expression as well as reading. As such, it is very important to the daily functioning and quality of life of individuals with Down syndrome.

\section{A Potential Solution: Rehearsal Training}

In typical development, there is clear improvement in working memory functioning through childhood. One reason for this improvement is that children develop more effective rehearsal strategies (see Cowan, 1997; Flavell, Beach and Chinsky, 1966; Ornstein, Naus \& Stone, 1977). For example, Ornstein, et al. (1977) found second graders rehearsed only one or two items together whereas sixth graders rehearsed more than two items together (see also Ornstein, Naus \& Liberty, 1975). When trained, second graders were able to learn to rehearse more items together and when they did, their recall became similar to that of sixth-graders. Fergusen and Bray (1976) suggested that the ordered repetition of items involved in rehearsal was key to memory improvement. They found that first graders who were trained to repeat items in order did better on the memory test than those trained to repeat items one at a time, to simply label items, or to use their own method. Many other studies have shown that children and adults can improve their immediate memory performance by adopting active rehearsal strategies (e.g., Ford, Pelham \& Ross, 1984; Henry, 1991; Ornstein \& Naus, 1983)

There has been great interest in applying rehearsal strategies to the training of individuals with intellectual disabilities. Rehearsal training studies have shown that, when instructed to use a rehearsal strategy, individuals with intellectual disabilities can use it and their short-term memory performance improves (e.g., Butterfield, Wambold \& Belmont, 1973; Brown, Campione, Bray \& Wilcox, 1973; Conroy, 1978; Hulme \& Mackenzie, 1992; Kellas, Ashcraft \& Johnson, 1974; Turnbull, 1974). Brown, Campione and Murphy, (1974) found that the effects of their 10-day training lasted over a six-month period. The most commonly used rehearsal strategy in this research is the overt cumulative rehearsal strategy, in which participants receive one new list item at a time, and each time they receive a new list item they repeat the entire list from the beginning. For example, suppose participants view a set of four pictures- car, tree, book, and chair. They see car first and say, "car." Then they see tree and say, "car, tree." Then they see book and say, "car, tree, book." Finally, they see chair and say, "car, tree, book, chair."

It is also now clear that rehearsal training can improve working memory in individuals with Down syndrome (Broadley \& MacDonald, 1993; Comblain, 1994; Laws, MacDonald \& Buckley, 1996). For example, Broadley and MacDonald (1993) showed that, after 12 20-minute ses- 
sions of rehearsal training over 6 weeks, children with Down syndrome (mean age $=8.4$ ) performed better than no-training controls (mean age $=9.5$ ) on most word span measures administered. Using a slightly older group with 18 15-minute sessions of rehearsal training over 6 weeks, Laws et al., (1996) found small but significant gains on some though not all span measures. Finally, Comblain (1994) found that, after eight 30-minute training sessions over eight weeks, rehearsal-trained individuals with Down syndrome improved on memory span tests, whereas untrained controls did not. This study included children, adolescents, and adults (mean age $=16.9$, mean mental age $=4.07$ ). Trends suggested that the training was more effective for the children and adolescents than the adults, but only 4 in each age group received training, so this is difficult to interpret.

As part of their study, Broadley and MacDonald (1993) compared rehearsal training with organisation training. The organisation training involved teaching category names and exemplars and providing practice on them in a game context (see Broadley, 1994). Half their training group received six weeks of rehearsal training followed by six weeks of organisation training, whereas the other half received the opposite schedule. Assessments taken before the switch indicated that rehearsal training was more effective in increasing memory span, whereas organisation training was more effective in increasing categorization. Thus, improvements were training-specific. This suggests that to improve auditory working memory, a rehearsal strategy would be more desirable than an organisation strategy. However, it also suggests that different types of training are not necessarily redundant, and using more than one type can enhance the breadth of improvement. At the end of the two six-week training periods, the trained children performed better at both word span and categorization measures than untrained children.

\section{Issue I: Auditory modality}

In early rehearsal training studies involving individuals with intellectual disabilities, little attention was paid to modality. In these studies, etiology of intellectual disability was either unknown or mixed and there was no special reason to make a distinction between auditory and visual working memory. In most of these studies, visual materials were used for both training and test. Thus, we know little about the prospects of using rehearsal training to improve auditory working memory per se. In one study in which auditory materials were used, results were equivocal. Hulme and Mackenzie (1992) used a totally auditory cumulative rehearsal training routine to boost the auditory memory span of adolescents with intellectual disabilities of mixed aetiology. Over the 10-day training period, the training group improved significantly on word span but not on digit span. On word span, the training group improved significantly more than an idle control group, but not more than a "repeatedly tested" control group. The failure to find significant improvement in digit span may have been due to a small sample size $(\mathrm{n}=8)$ and a limited training period.
For individuals with Down syndrome, there is a special concern for improving auditory working memory because it tends to be weaker than visual working memory. Thus, one important issue in memory training for individuals with Down syndrome is whether rehearsal training can be effective in improving auditory working memory. Broadley and MacDonald (1993) reported that, although rehearsal training was more effective than organisation training in increasing memory span measures, this did not apply to the auditory-only measures- on these there was no difference between the groups. Also, both trained groups improved more than the control group on all measures of visual memory. However, only the trained group that had rehearsal training second improved more than the control group on measures of auditory memory, and only on a few of the auditory memory measures.

The greater improvements for visual than auditory working memory in the Broadley and MacDonald (1993) study may be due to the fact that auditory working memory is particularly weak individuals with Down syndrome and may be more resistant to training. However, the cumulative rehearsal training in the study used pictures heavily, making the training activities more similar to the visual memory tests than to the auditory memory tests. In other words, the training may have prepared children better to perform well on visual memory tests than to perform well on auditory memory tests. Laws et al. (1996) also used visual training materials, and found modest improvement in auditory word span but not auditory digit span. For both word span and digit span, there was a trend toward less improvement in the auditory than the visual modality, though the differences were not significant.

Comblain's (1994) study involved cumulative rehearsal training that began with pictures but phased them out over sessions until children were left with only finger cues to mark new items. Using this training, Comblain found clear and significant differences between trained and untrained groups on a composite auditory memory span measure. Visual memory was not measured. Possibly, improvements in auditory working memory are more likely if the training relies on auditory processing moreso than visual processing. In the present study we were especially interested in improving auditory working memory, and we set up the training to be totally auditory with no visual materials at all. To compensate for the lack of visual assistance in the training, we set up a longer training period than has been typical.

\section{Issue 2: Maintenance}

If rehearsal training is to make an impact on learning and communication in the lives of individuals with Down syndrome, we need to know how long the impact of the training can last and what must be done to achieve really meaningful effects. Follow-up assessments to date have shown that the effects of rehearsal training can last several months. Two and eight-months following the training in the Broadley and MacDonald (1993) study, trained children generally maintained their levels of improvements, 
and were still performing better than the control children who were still in the study (18 of the original 26). Improvements in visual working memory seemed to maintain better than those in auditory working memory (Broadley, MacDonald \& Buckley, 1994). Six-weeks and six months following the training in the Comblain (1994) study, trained individuals declined from posttest, but they still performed better than at pretest. Untrained individuals did not change over the various assessments.

Although training effects can last for several months, they may dissipate eventually. Only one follow-up study has examined maintenance over a period of time greater than one year. Laws, MacDonald, Buckley and Broadley (1995) reported that three years after training in the Broadley and MacDonald (1993) study, gains made had subsided. Fourteen of the original 25 trained children performed similarly to a same-age matched untrained group. Their memory performance was above what it was pretraining, but it dropped from earlier assessments, and the difference between pretraining and 3 -year follow-up was more likely due to development than to the training. One of the most important next steps in research on rehearsal training of individuals with Down syndrome is to find a way to make improvements last years rather than months. Periodic maintenance activities may be the answer.

One way to encourage maintenance activities is to teach parents the training routine so they can use it with their children at home. After the intensive period of memory training, parents can work with their children from time to time so that any gains in working memory and related abilities will be maintained. Broadley and MacDonald (1993) had this idea in mind in their training study (see also Laws et al., 1996). Eleven of their 26 trained children received their training from a "keyworker," who was either a teacher, a non-teaching assistant, or a parent. In fact, there was some evidence that keyworker-trained children maintained improvements over eight months better than the experimenter-trained children (Broadley et al., 1994); however, the keyworker-trained children were higher in general ability at the beginning of the training. Thus, it is difficult to know whether the difference in maintenance was due to the type of trainer or the difference in general ability. Further, it is not clear how many of the 11 keyworkers were parents and how many were teachers and non-teaching-assistants. Laws et al. (1996) found that, though teacher-trained children at two schools improved in word span, those from a third school who were parenttrained did not. The parent training was set up because teachers at the third school declined to participate. It is possible that children did not benefit from the training because they were different in some way from the children at the other schools, or because they were being trained by their parents in their home. Thus, there is still a need to investigate the feasibility of parents as trainers. The present study was designed to be totally parent-oriented, with parents as the only trainers.

\section{Issue 3: Control comparisons}

A very powerful test of the effectiveness of a training routine is to compare the training group to a group that is similar in the number of contacts, amount of special attention, practice on focusing attention, and positive reinforcement. Without this type of comparison, some of the improvement on assessments may be due to increased familiarity and comfort with the experimenter, motivation, and ability to complete tasks. Most of the rehearsal training studies described in the present paper did not use this type of control comparison. Most used an idle control group which only completed assessments at various intervals. In one exception from the studies using mixed-aetiology studies, Hulme and Mackenzie (1992) used a "repeatedly tested" control group as well as an idle control group. Adolescents in the repeatedly tested control group met with the experimenter the same amount of time as those in the rehearsal group, but rather than use an overt cumulative rehearsal procedure, they simply repeated back lists. The rehearsal and repeatedly tested groups performed similarly, showing improvement on word span but not on digit span. Thus, it appeared that there was no great advantage of the cumulative rehearsal training over simple practice. Next, we would like to know if there is any advantage of either of these methods beyond the adult attention and reinforcement afforded by them.

In Broadley and MacDonald's (1993) study involving children with Down syndrome, the rehearsal training group was compared with the organisation training group after six weeks of training. As noted already, their organisation training involved teaching category names and exemplars. It was less similar to the rehearsal training than was Hulme and Mackenzie's (1992) repeated testing condition, yet it involved one-on-one adult attention and reinforcement. The finding that the rehearsal training group performed better on several memory span tests than the organisation training group is very important because it indicates that it is indeed the training itself that resulted in the improvements. In our in-progress study, we are using a "visual activities" comparison condition, in which there was no memory training, but instead, parents work with their children on various visual activities for the same amount of time as they would work on memory training.

\section{The present study: In-progress}

In the present section, we describe our own in-progress study, and use the preliminary results to address two of the three issues raised earlier in the paper. One is the issue of whether auditory working memory can be improved in individuals with Down syndrome. Our training and tests are auditory. The other is the issue of whether improvements related to rehearsal training will hold up to more stringent control comparisons. Our control comparison involves roughly equivalent contact time and one-on-one attention from a parent, but no memory activities. The study addresses the remaining issue of whether memory improvements can be lasting by having parents be the train- 
ers. We present anecdotal information on whether parents can be good trainers. However, the preliminary results can not address the effectiveness of this approach in producing working memory improvements that last.

In the present study, parents learn to follow a totally auditory overt cumulative rehearsal training routine with their children with Down syndrome. Half the families are in the "Memory-first" condition and half are in the "Visualfirst" condition. The Memory-first families begin with 3 months of memory training, then switch to 3 months of visual activities, and then return to 3 months of memory training. The Visual-first families have the opposite schedule. The visual activities serve as a control condition in which the amount of one-on-one time and attentional requirements are similar to the memory training. They include a variety of visually-based workbook activities, such as colouring, shape matching, and connect-the-dots. Before the first 3-month period and after each following 3-month period, parents bring their children to the lab for memory/ language assessment. These assessments serve as pre- and posttests. Because the study is ongoing, we can only report preliminary data here. We can report early results from the first 3-month period, which has been completed by six Memory-first families and five Visual-first families. For the present report, we address two questions- (1) Can parents be good trainers? and (2) Can auditory working memory improve with parents as trainers?

\section{Method}

\section{Participants}

Children were eligible for the study if they were between 6 and 14 years old, could imitate verbally at least one word at a time, had no more than a mild hearing loss in the better ear, lived at home within a 2 -hours drive of our laboratory, had a telephone at home and a parent who was willing to participate. All children had Down syndrome verified by chromosomal analysis. Table 1 contains characteristics of the subsample reported here. In the sub-sample, there were two girls and four boys in the Memoryfirst group, and five boys in the Visual-first group.

\section{Pre/posttests}

Children complete the following pre/ posttests.

\section{Digit span}

Adapted from the Digit span subtest of the Wechlser Intelligence Scale for Children, $3^{\text {rd }} \mathrm{ed}$. (WISC-III), this test measures auditory working memory. It requires children to listen to increasingly long lists of digits and repeat back verbatim. Scoring was reflected as the length of list the participant could repeat back reliably.

\section{Counting span}

Modelled after a task used by Case, Kurland and Goldberg (1982), this task taps more general working memory, and reflects both storage and processing aspects of working memory. Children count the green dots on an index card, turn it over, and report the number of green dots. If they can do that, they advance to two index cards. They count the dots on the first card, turn it over, count the dots on the second card, turn it over, then report the number of dots from the first card followed by the number of dots from the second card. The task goes up to five cards, but testing is discontinued if a child misses all three trials at a particular level. The task combines both visual and auditory presentation, in that the dots are presented visually but are counted aloud by the children. Scores are number of trials correct of 15 (3 trials at each level $x$ levels).

\section{Sentence memory}

From the Woodcock-Johnson Psychoeducational Battery, this test reflects auditory working memory as assisted by language processing. Children listen to increasingly long phrases and sentences, and repeat them back verbatim. Scores are expressed as age-equivalents.

\section{Other tasks}

Not included in this report are Listening comprehension, Phonological similarity, Day/Night central executive task, and Category fluency. We hope to use them eventually to address questions regarding the impact of training on specific aspects of working memory and on language processing.

\section{Working memory training}

The training involves overt cumulative rehearsal. Children listen to a list of unrelated digits or words. Each time they hear a new digit or word, they repeat the list from the beginning. For example, the parent begins the list 4-7-2 by

\begin{tabular}{|c|c|c|c|c|}
\hline & \multicolumn{2}{|c|}{$\begin{array}{l}\text { Memory-first Group } \\
(n=6)\end{array}$} & \multicolumn{2}{|c|}{$\begin{array}{l}\text { Visual-first Group } \\
(n=5)\end{array}$} \\
\hline & Mean & SD & Mean & SD \\
\hline Age & 10.9 & 2.6 & 10.7 & 3.0 \\
\hline Nonverbal IQ & 49.8 & 13.7 & 49.0 & 15.4 \\
\hline \multicolumn{5}{|l|}{ Pretests } \\
\hline Digit span $^{a}$ & 1.8 & 0.9 & 2.3 & 0.4 \\
\hline Dot-counting ${ }^{b}$ & 3.2 & 2.6 & 3.0 & 2.1 \\
\hline Sentence memory ${ }^{c}$ & c $2.9(2-10)$ & 0.5 & $2.7(2-8)$ & 0.4 \\
\hline \multicolumn{5}{|l|}{ Posttests } \\
\hline Digit span ${ }^{a}$ & 2.8 & 1.0 & 2.6 & 0.7 \\
\hline Dot-counting ${ }^{b}$ & 4.0 & 3.1 & 2.4 & 2.6 \\
\hline Sentence memory ${ }^{c}$ & c $3.0(3-0)$ & 0.2 & $2.9(2-10)$ & 0.2 \\
\hline
\end{tabular}

Table I. Group Characteristics and Performance on Pre/posttest Memory Measures over 3 Months

a number of items repeated back. ${ }^{b}$ number of trials correct of I5. c Age-equivalent score in years. In parenthesis is the age-equivalent score converted to years and months. 
saying, " 4. ." The child repeats, " 4 ". The parent gives the next list item, "7." The child repeats, "4-7." The parent gives the final list item, "2." The child repeats, "4-7-2."

Each child begins with a Learning Phase in which he or she simply learns the repeating-back procedure. In this phase, the parent demonstrates using a favourite stuffed animal, and there are only two items in each list. When the child meets a criterion of 3 in a row correct without prompts, he or she advances to the Memory Phase. In the Memory Phase, the number of items per list increases to 3 . When a criterion of 3 in a row correct is achieved, the number of items per list increases to 4 and, when applicable, to 5 . Each new session begins with a Learning Phase as a review of the procedure. During the sessions, if the child is struggling to remember an item, the parent can give an auditory prompt (the first sound of the item). For each list attempted, the parent records "correct," "correct with prompts," or "incorrect." The parent follows a reinforcement schedule that includes response-level, session-level, and criterionlevel reinforcers chosen by the parent based on the child's interests. There are 5 10-minute sessions per week for 3 months. The parent records the data and tape records the sessions.

\section{Results}

\section{Can parents be good trainers?}

The parents' data sheets and the tape-recordings of training sessions allow us to answer this question. Indeed, parents have been successful at following the training procedure, though most have needed minor corrections at the beginning. They have followed the reinforcement procedure, but some have needed correction. They have recorded data diligently and when they have followed the procedure and reinforcement routine, the data appear to be very accurate. We

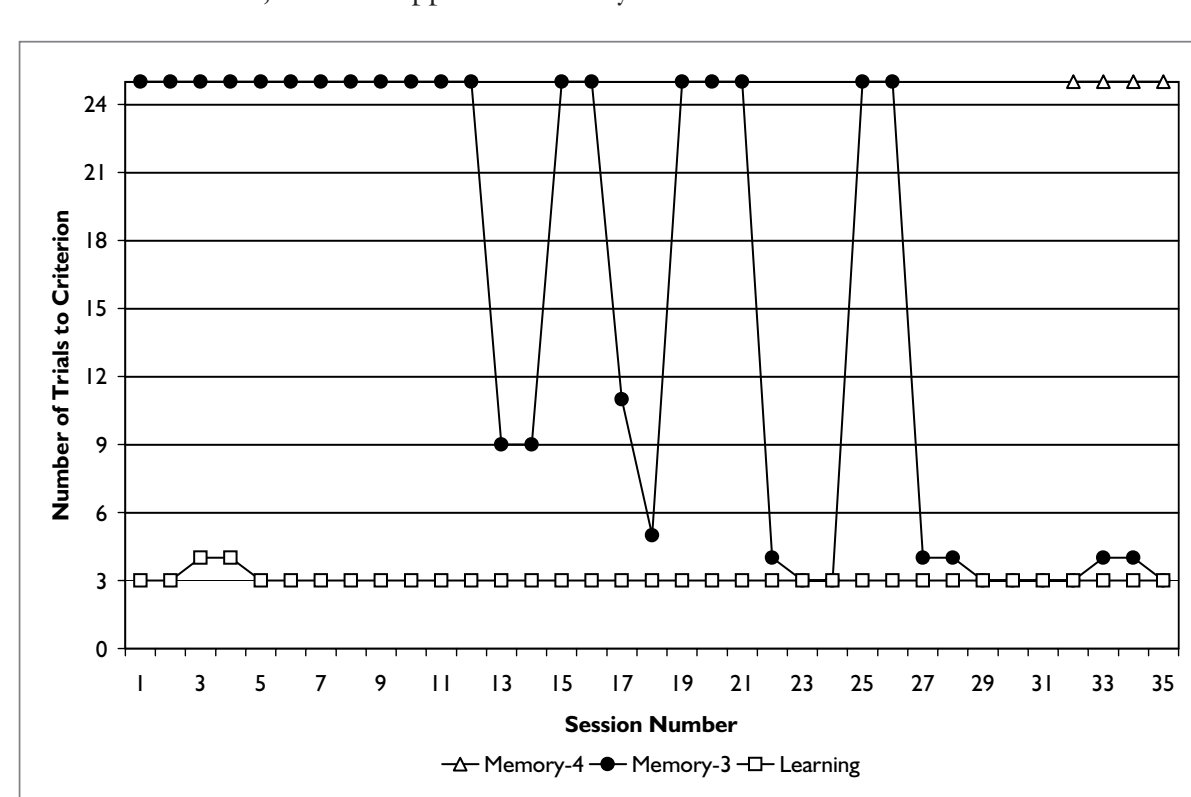

Figure I. Trials needed to reach criterion for Learning and Memory phases for participant no. I in each 10 -minute training session (criterion $=3$ trials or lists in a row correctly repeated back without prompts). Points above 24 indicate failure to meet criterion in the designated training session. are currently working on a data-based reliability study so that we can answer this question more precisely. Finally, as might be expected, there is some variability in how closely parents have kept to the 5 -sessions-per-week schedule. The range is 2.5 to 5.1 sessions per week. Thus, the Memoryfirst children did not all have the same amount of training. Our study sacrifices a degree of experimental control in order to find out whether training can be effective in the real world of family life.

\section{Can auditory working memory improve with parents as trainers?}

We present two forms of data relevant to whether auditory working memory improved during the first 3 -month period of the study. First, we present the session-to-session data from the training for the first child to complete the training period (Figure 1). In Figure 1, the number of trials needed to meet criterion in the Learning phase and Memory phase (with 3 and with 4 items per list) are shown for each training session completed in the 3 -month period. Points that are above 24 represent failure to meet criterion during the session. With this type of data, improvement in auditory working memory would be indicated by a decrease over sessions in the number of trials to criterion and advancement from one phase to the next (Learning Memory-3 to Memory-4). As shown in Figure 1, Participant number 1 met criterion in the Learning phase in the first session, indicating that she learned the repeating back procedure easily. However, it took her about 13 sessions before she met criterion in the Memory phase with 3 -item lists. She had a period in which she sometimes met criterion and sometimes did not. Finally, she met criterion consistently and easily. At this point she began 4 -item lists, but she did not meet criterion before her 3-month training period ended. Each child has a unique pattern of progress, with some showing faster progress than others. Although this child is not unusual in her rate of progress, her pattern may be more stable than many of the others.

The second type of data we present is the pretest-posttest assessments of auditory working memory. It is in this comparison that we can say whether improvements hold up to our relatively rigorous control comparison. Table 1 provides preand posttest group means and standard deviations for the Digit span, Counting span, and Sentence memory tasks. On Digit span, the Memory-first group improved significantly by almost a whole digit, which represents about a $50 \%$ gain, $t(5)=2.86$, $S E M=0.32, p<.05$. The Visual-first group did not improve 
significantly. On Counting span, the Memory-first group improved a bit, whereas the Visual-first group decreased a bit. These changes are not statistically significant, and we will have to wait for data from more children to assess the effect of the memory training on this task. On Sentence memory, age-equivalent scores increased by approximately 2 months over the 3 -month period. This amount of gain is impressive for the children in the study who, at 10 years old are only doing as well as a 2-year-old on this task. Because the gain is present for both groups, however, it cannot be attributed to the memory training. It could be related to increased demand in both conditions for listening to instructions, or it could be a testing effect.

\section{Tentative Conclusions}

Previous research has indicated that rehearsal training can improve working memory in individuals with Down syndrome. We designed the present study in part to address three issues that are still not resolved- targeting auditory working memory, maintenance of improvement, and control comparisons. Unlike in most previous studies, the rehearsal training in the present study was totally auditory, it was administered only by parents, and an alternate-activity control comparison was used. Our preliminary results suggest that dedicated parents can be good trainers and auditory working memory can improve with parents as trainers. This improvement is above and beyond any advantage related to parents sitting down with their children oneon-one on a regular basis to do instructional activities (e.g. increased practice in, attention for, and praise for focusing attention, following instructions, and engaging in conversation). The most reliable improvements and those most clearly linked to the rehearsal training are in digit span, the task most similar to the training. Any gain in sentence memory (nonsignificant at this point) appears to be equivalent in both groups. These conclusions are highly tentative, however, because our data collection is not yet complete.

If improvements in auditory working memory are to have any utility, they will enable higher-order cognitive functions such as language processing. In our preliminary data, however, there is no evidence yet that improvements in auditory working memory lead to improvements in language processing. Even our measure of language-assisted auditory working memory (sentence memory) shows no improvement that is specifically related to the training. However, our samples are very small and improvements in memory/language measures may emerge as more children complete the first phase of the study. Still, for language improvements that are enabled specifically by improvements in auditory working memory, it may be that a time lag is to be expected. The language improvement may not emerge until several months after the initial improvement in auditory working memory. If so, we may see some improvement in sentence memory and other memory/language tasks at the 6- and 9-month assessments.

The challenge today in research and practice is to find ways of turning improvement in working memory into long-last- ing and meaningful improvements in general areas of functioning. In the field of intellectual disabilities, it has been relatively easy to train a skill or expand a cognitive capacity. It has been very difficult, however, to train transfer of the skill to meaningful domains. To accomplish this task, we will need to examine the time lag relations between improvements in working memory and improvements in higher-order functioning such as language, reading, calculation, reasoning, and spatial processing. We will also need to examine the impact of maintenance activities and schedules on continued improvement of working memory as well as on improvement in higher-order functioning.

\section{Acknowledgements}

The research described in this paper is currently supported by Grant HD37445 from the National Institute of Child Health and Human Development, jointly with the National Down Syndrome Society. This article is based on a presentation at the $3^{\text {rd }}$ International Conference on Language and Cognitive Development in Down Syndrome, 2000, Portsmouth, UK.

\section{Correspondence}

Frances A. Conners • Box 870348, Tuscaloosa, AL 35487-0348 USA•Email fconners@bama.ua.edu

\section{References}

Abbeduto, L. (2001). The language and cognitive profile in Down syndrome: Evidence from a comparison with fragile-X syndrome. Down Syndrome Research and Practice, 7 (1), 9-15.

Adams, J. W., \& Hitch, G. J. (1997). Working memory and children's mental addition. Journal of Experimental Child Psychology, 67, 21-38.

Baddeley, A. D. (1982). Reading and working memory. Bulletin of the British Psychological Society, 35, 414-417.

Baddeley, A. D. (1986). Working Memory. Oxford: Oxford University Press.

Baddeley, A. D., \& Hitch, G. (1974). Working memory. In G. H. Bower (Ed.), Recent Advances in Learning and Motivation (Vol. 8, pp. 47-89). New York: Academic Press.

Baddeley, A. D., \& Hitch, G. (1994). Developments in the concept of working memory. Neuropsychology, 8, 485-493.

Broadley, I. W. (1994). Teaching short-term memory skills to children with Down syndrome. Unpublished Ph.D. thesis, University of Portsmouth, Portsmouth, UK.

Broadley, I., \& MacDonald, J. (1993). Teaching short term memory skills to children with Down syndrome. Down Syndrome Research and Practice, 1, 56-62.

Broadley, I., MacDonald, J., \& Buckley, S. (1994). Are children with Down syndrome able to maintain skills learned from a short-term memory training programme? Down Syndrome Research and Practice, 2, 116-122.

Broadley, I., MacDonald, J. \& Buckley, S. (1995). Working memory in children with Down syndrome. Down Syndrome Research and Practice, 3, 3-8. 
Brown, A. L., Campione, J. C., Bray, N. W., \& Wilcox, B. L (1973). Keeping track of changing variables: Effects of rehearsal training and rehearsal prevention in normal and retarded adolescents. Journal of Experimental Psychology, $101,123-131$.

Brown, A. L., Campione, J. C., and Murphy, M. D. (1974). Keeping track of changing variables: Long-term retention of a trained rehearsal strategy by retarded adolescents. American Journal of Mental Deficiency, 78, 446-453.

Butterfield, E. C., Wambold, C., \& Belmont, J. M. (1973). On the theory and practice of improving short-term memory. American Journal on Mental Retardation, 77, 654-669.

Carlesimo, G. A., Marotta, L., \& Vicari, S. (1997). Longterm memory in mental retardation: Evidence for a specific impairment in subjects with Down syndrome. Neuropsychologia, 35, 71-79.

Case, R., Kurland, M., \& Goldberg, J. (1982). Operational efficiency and the growth of short-term memory span. Journal of Experimental Child Psychology, 33, 386-404.

Chapman, R. S. (1995). Language development in children and adolescents with Down syndrome. In P. Fletcher, \& B. MacWhinney (Eds.), The Handbook of Child Language (pp. 641-663). Cambridge, MA: Blackwell.

Chapman, R. S. (2001). Language, cognition and short-term memory in individuals with Down syndrome. Down Syndrome Research and Practice, 7 (1), 1-7.

Comblain, A. (1994). Working memory in Down syndrome: Training the rehearsal strategy. Down Syndrome Research and Practice, 2, 123-126.

Conroy, R. L. (1978). Facilitation of serial recall in retarded children and adolescents: Verbal and kinesthetic strategies. American Journal of Mental Deficiency, 82, 410-413.

Cowan, N. (1997). The development of working memory. In N. Cowan (Ed.), The Development of Memory in Childhood (pp. 163-199). Hove, England: Psychology Press/ Erlbaum.

Dykens, E. M., Hodapp, R. M., \& Finucane, B. M. (2000). Genetics and Mental Retardation Syndromes. Baltimore: Paul H. Brookes.

Fergusen, R. P., \& Bray, N. W. (1976). Component processes of an overt rehearsal strategy in young children. Journal of Experimental Child Psychology, 21, 490-506.

Flavell, J. H., Beach, D. R., \& Chinsky, J. H. (1966). Spontaneous verbal rehearsal in a memory task as a function of age. Child Development, 37, 283-299.

Ford, C. E., Pelham, W. E., \& Ross, A. O. (1984). Selective attention and rehearsal in the auditory shortterm memory task performance of poor and normal readers. Journal of Abnormal Child Psychology, 12, 127-141.

Fowler, A. E., Gelman, R., \& Gleitman, L. R. (1994). The course of language learning in children with Down syndrome. In H. Tager-Flusberg (Ed.), Constraints on Language Acquisition: Studies of Atypical Children (pp. 91-140). Hillsdale, NJ: Erlbaum.

Gathercole, S. E., \& Baddeley, A. D. (1990). Phonological memory deficits in language disordered children: Is there a causal connection? Journal of Memory and Language, 29, 336-360.
Gathercole, S. E., \& Baddeley, A. D. (1993). Working Memory and Language. Hillsdale, NJ: Erlbaum.

Henry, L. A. (1991). Development of auditory memory span: The role of rehearsal. British Journal of Developmental Psychology, 9, 493-511.

Hulme, C., \& Mackenzie, S. (1992). Working Memory and Severe Learning Difficulties. Hillsdale, NJ: Erlbaum.

Jarrold, C. \& Baddeley, A. D. (2001). Short-term memory in Down syndrome: Applying the working memory model. Down Syndrome Research and Practice, 7 (1), 17-23.

Jarrold, C., Baddeley, A. D., \& Hewes, A. K. (1999). Genetically dissociated components of working memory: Evidence from Down's and Williams syndrome. Neuropsychologia, 37, 637-651.

Jarrold, C., Baddeley, A. D., \& Hewes, A. K. (2000) Verbal short-term memory deficits in Down syndrome: A consequence of problems in rehearsal? Journal of Child Psychology and Psychiatry, 40, 233-244.

Kay-Raining Bird, E., \& Chapman, R. S. (1994). Sequential recall in individuals with Down syndrome. Journal of Speech and Hearing Research, 37, 1369-1380.

Kellas, G., Ashcraft, M. H., \& Johnson, N. S. (1974). Rehearsal processes in the short-term memory performance of mildly retarded adolescents. American Journal of Mental Deficiency, 77, 670-679.

Kintsch, W., \& van Dijk, T. A. (1978). Toward a model of text comprehension and production. Psychological Review, 85, 363-394.

Laws, G., MacDonald, J., \& Buckley, S. (1996). The effects of a short-term training in the use of a rehearsal strategy on memory for words and pictures in children with Down syndrome. Down Syndrome Research and Practice, 4, 70-78.

Laws, G., MacDonald, J., Buckley, S., \& Broadley, I. (1995). Long-term maintenance of memory skills taught to children with Down syndrome. Down Syndrome Research and Practice, 3, 103-109.

Logie, R. H., Gilhooly, K. J., \& Wynn, V. (1994). Counting on working memory in arithmetic problem solving. Memory and Cognition, 22, 395-410.

Mackenzie, S., \& Hulme, C. (1987). Memory span development in Down syndrome, severely subnormal, and normal subjects. Cognitive Neuropsychology, 4, 303-319.

Marcell, M. M., \& Armstrong, V. (1982). Auditory and visual sequential memory of Down syndrome and nonretarded children. American Journal of Mental Deficiency, 87, 86-95.

Marcell, M. M., Harvey, C. F., \& Cothran, P. (1988). An attempt to improve auditory short-term memory in Down's syndrome individuals through reducing distractions. Research in Developmental Disabilities, 9, 405-417.

Marcell, M. M., Ridgeway, M. M., Sewell, D. H., \& Whelan, M. L. (1995). Sentence imitation by adolescents and young adults with Down's syndrome and other intellectual disabilities. Journal of Intellectual Disability Research, 39, 215-232.

Marcell, M. M., \& Weeks, S. L. (1988). Short-term memory difficulties and Down's syndrome. Journal of Mental Deficiency Research, 32, 153-162.

McDade, H. L., \& Adler, S. (1980). Down syndrome and short-term memory impairment: A storage or retrieval 
deficit? American Journal of Mental Deficiency, 84, 561-567.

Ornstein, P. A., \& Naus, M. J. (1983). "Rehearsing” according to artificially generated rehearsal patterns: An analysis of active rehearsal. Bulletin of the Psychonomic Society, 21, 419-422.

Ornstein, P. A., Naus, M. J., \& Liberty, C. (1975). Rehearsal and organizational processes in children's memory. Child Development, 46, 818-830.

Ornstein, P. A., Naus, M. J., \& Stone, B. P. (1977). Rehearsal training and developmental differences in memory. Developmental Psychology, 13, 15-24.

Pennington, B. F., \& Bennetto, L. (1998). Toward a neuropsychology of mental retardation. In J. A., Burack, R. M. Hodapp, \& E. Zigler (Eds.), Handbook of Mental Retardation and Development (pp. 80-114). New York: Cambridge University Press.

Pulsifer, M. B. (1996). The neuropsychology of mental retardation. Journal of the International Neuropsychological Society, 2, 159-176.

Silverstein, A. B., Legutki, G., Friedman, S. L., \& Takayama, D. L. (1982). Performance of Down syndrome individuals on the Stanford-Binet Intelligence Scale. American Journal of Mental Deficiency, 86, 548-551.

Turnbull, A. (1974). Teaching retarded persons to rehearse through cumulative overt labeling. American Journal of Mental Deficiency, 79, 331-337.
Varnhagan, C. K., Das, J. P., \& Varnhagan, S. (1987) Auditory and visual memory span: Cognitive processing by TMR individuals with Down syndrome or other etiologies. American Journal of Mental Deficiency, 91, 398-405.

Vicari, S. (2001). Implicit versus explicit memory function in children with Down and Williams syndrome. Down Syndrome Research and Practice, 7 (1), 35-40.

Vicari, S., Bellucci, S., \& Carlesimo, G. A. (2000). Implicit and explicit memory: A functional dissociation in persons with Down syndrome. Neuropsychologia, 38, 240-251.

Vicari, S., Carlesimo, G. A., \& Caltagirone, C. (1995). Shortterm memory in persons with intellectual disabilities and Down's syndrome. Journal of Intellectual Disability Research, 39, 532-537.

Wang, P. (1996). A neuropsychological profile of Down syndrome: Cognitive skills and brain morphology. Mental Retardation and Developmental Disabilities Research Reviews, 2, 102-108.

Wishart, J. (1996). Learning in young children with Down's syndrome: Developmental trends. In J. A. Rondal, J. Perera, L. Nadel, \& A. Comblain (Eds.), Down's Syndrome: Psychosocial, Psychobiological, and Socio-Educational perspectives. San Diego: Singular Publishing Group. 